\title{
A STUDY OF KNOWLEDGE MANAGEMENT ENABLERS ACROSS COUNTRIES
}

\author{
Rémy Magnier-Watanabe, University of Tsukuba, Tokyo \\ Caroline Benton, University of Tsukuba, Tokyo \\ Dai Senoo, Tokyo Institute of Technology, Tokyo
}

\begin{abstract}
Knowledge has been long cited as a strategic asset and a source of competitive advantage for organizations. However, the creation of knowledge is a complex process that is influenced by several factors beyond the typical practice of knowledge management. In this research, we assess the effects of leadership, Ba (shared context in motion), organizational culture, organizational control and work style on knowledge management defined in terms of the SECI process of socialization, externalization, combination, and internalization. Based on data gathered from a questionnaire survey of a Japanese pharmaceutical company and its subsidiaries in the United States, France, and China, we compare how the aforementioned organizational factors influence the processes of knowledge management in these organizations. The results show that organizational factors affect knowledge management practices differently in each of the targeted countries, and suggest that knowledge management activities need to be tailored to the organizational idiosyncrasies of each local office, without betraying the global vision of the corporation.
\end{abstract}

\section{Keywords}

Knowledge management practice, Decision support, Culture

\section{INTRODUCTION}

Knowledge management (KM) has been recognized as being central to product and process innovation, executive decision making, and organizational adaptation and renewal (Earl, 2001). However, existing KM frameworks - that distinguish for instance knowledge 
from information or explicit knowledge from tacit knowledge - do not easily suggest what KM interventions or investments an organization should make. Zack (1998) cites several field studies related to the motivating factors for KM projects (Davenport et al., 1998; Ruggles, 1998; Leidner, 1998), and states that the link between KM and business strategy, although frequently mentioned, has been widely ignored in practice.

In the resource-based view of the firm, internal resources and capabilities are the main source of competitive advantage, and firms should position themselves strategically based on their unique, valuable, and inimitable resources and capabilities rather than on the external positioning of products and services derived from those capabilities (Barney, 1996; Collis and Montgomery, 1995; Grant, 1991; Prahalad and Hamel, 1990). When viewed as a dynamic organizational capability, knowledge management can help the firm innovate to achieve congruence with the changing business environment (Teece et al., 1997; Kusunoki et al., 1998; Eisenhardt and Martin, 2000).

However, KM is a complex process and Turner and Makhija (2006) suggest that "any given control mechanism has the capacity to affect both the nature and flow of knowledge in a firm by the manner in which it processes particular attributes of knowledge” (p. 213). In addition, organizational climate and organizational structure have been recognized as shaping knowledge management (Chen and Huang, 2007). In fact, previous research has shown that the organization of the firm - such as its structure, membership, relationships, and strategy constrain and influence the nature of KM (Magnier-Watanabe and Senoo, 2008). There has, however, been little research on how all this factors taken together affect knowledge management, especially in the context of the global business market. This paper investigates the influence of these factors across cultures with a survey of a Japanese pharmaceutical company and its international subsidiaries.

This paper presents in section two the concepts of knowledge management and its enabling factors. Then, section three describes our hypotheses and research model and section four reviews the quantitative analysis conducted on the data set. Section five is a discussion of the study's findings and section six concludes this research. 


\section{LITERATURE REVIEW}

\section{Knowledge Management}

The premise of the "knowledge creation theory" is the supposition that knowledge can be classified as either tacit or explicit (Polanyi, 1966). Tacit knowledge is subjective knowledge that is hard to express with language, diagrams, figures or numbers: for example, beliefs, points of view, technical skills and know-how are all forms of tacit knowledge. On the other hand, explicit knowledge is objective and rational and can be expressed with language, numbers or formulas: texts, equations, technical specifications and manuals are a few examples.

In the knowledge-creating view of the firm, the conversion process between tacit and explicit knowledge - Socialization, Externalization, Combination, and Internalization - helps synthesize subjective knowledge and values into objective and socially shared organizational knowledge (Nonaka, 1994; Nonaka and Takeuchi, 1995). The knowledge-creation process starts with socialization where the tacit knowledge of customers and competitors is acquired through the creation of a dense field of interactions. That knowledge is then externalized, or conceptualized, through dialogue into explicit knowledge to be shared within the firm. Next, the explicit knowledge, which is now in a form appropriate for diffusion throughout the organization, is combined with other existing explicit knowledge to form a more complete and practical set of knowledge. Subsequently, organizational members internalize the newly created complex set of explicit knowledge through application and action. Recent empirical studies have shown that there are various styles of managing this organizational knowledge creation process, and that although not all knowledge management styles equally impact performance (Lee and Choi, 2003; Chuang, 2004), both explicit and tacit knowledge should be managed simultaneously towards achieving greater results (Jordan and Jones, 1997). In a survey of Japanese small and medium manufacturing enterprises, Riera et al. (2009) have found that a balance of SECI modes correlated with higher levels of financial performance.

Thus, in today's business environment with its accelerating speed of change, the promotion of the knowledge-creation process expressed by the SECI model is an important method for creating knowledge, and hence innovation, for enhanced competitive advantage.

Several organizational factors have been identified as specifically enabling this process of knowledge creation. 


\section{Enabling Factors of Knowledge Creation}

Davenport and Prusak (1998) propose that the sharing of knowledge is not a natural act. The knowledge that is held and embodied in the minds of individuals is not usually readily given or received without incentives or an exchange mechanism. The reasons for this reluctance to share knowledge include the characteristics of knowledge itself (e.g. tacit knowledge is very difficult to share), and the individual and organizational barriers such as the reluctance to give away one's source of power or time and budget constraints respectively. We focus in this research on the organizational factors influencing KM.

A number of enablers of knowledge management have been recognized in previous research and many of these factors overlap (Von Krough et al., 2000; Malhotra and Majchrzak, 2004; Baskerville and Dulipovici, 2006). In comparing enablers of knowledge creation across countries, we categorize these organizational factors into five categories organizational culture, Ba, leadership, organizational control, and work style - consistent with the organizational enabling conditions put forth by Nonaka and Takeuchi (1995) and the key success factors of knowledge projects proposed by Davenport and Prusak (1998). The former team of researchers identified five enablers of knowledge creation at the organizational level: intention, autonomy, fluctuation and creative chaos, redundancy, and requisite variety (Nonaka and Takeuchi, 1995). The latter team recommended several factors leading to knowledge project success, such as knowledge-oriented culture, technical and organizational infrastructure, senior management support, modicum of process orientation, clarity of vision and language, and multiple channels for knowledge transfer (Davenport and Prusak, 1998).

We focus in this study on Davenport and Prusak (1998)'s enabling conditions and proceed to compare their relative importance for knowledge management across different cultures.

Organizational culture. The first factor, organizational culture, is described as a system of shared meaning held by organizational members that distinguishes one organization from another (Schein, 2004). This system of shared meaning allows members to understand the context and underlying meaning of the knowledge being shared. Organizational culture also serves as a sense-making and control mechanism that guides and shapes the attitudes and behaviors of employees (Robbins, 2003). In other words, organizational culture will 
determine, to a large extent, how members interact with one another. For example, a culture that is open and encourages discussion will promote communication and knowledge sharing, whereas an organizational culture that fuels suspicion and power struggle will greatly inhibit the free sharing and exchange of knowledge, which is a source of power, among organizational members. Von Krough et al. (2000) propose that a culture of care, where organizational members are mutually interested in the progress and well-being of one another, is necessary for active knowledge sharing. This construct is consistent with Davenport and Prusak (1998)'s knowledge-oriented culture. For the purpose of our research, we analyze the respondents' organizational culture in terms of their openness and bureaucratic nature, as communication, and hence knowledge sharing, will be affected significantly by this spectrum from open/free communication to closed/ formal communication.

Ba. With regards to the second factor, knowledge is not shared in a vacuum, but within a “contextualized space,” whether it is mental (e.g., shared experience, values), physical (e.g. an office, book or product), or virtual (cyber). Shimizu (1995) and Nonaka and Konno (1998) refer to this space as $\mathrm{Ba}$, a Japanese word roughly meaning place, which designates a specific time and place where interactions between individuals take place.

The concept of learning space, that builds on Kurt Lewin's field theory and his concept of life space (Marrow, 1977), is similar to that of Ba. For Lewin, both person and environment are interdependent variables, and behavior is a function of person and environment. One's position in the learning space defines that person's experience and thus defines their "reality". Lewin stresses the importance for education of defining the learning space in terms of the learner's experience (Kolb and Kolb, 2005): "One of the basic characteristics of field theory in psychology, as I see it, is the demand that the field which influences an individual should be described not in objective physicalistic terms, but in the way that it exists for that person at that time" (Cited in Cartwright, 1951: 62).

However, Ba must be appropriate for the knowledge that is to be shared. For example, explicit knowledge is easily codified and can be shared through a book or a physical Ba, whereas tacit knowledge that is complex, highly contextual and hard to codify, such as the expert knowledge of highly skilled craftsmen or veteran strategic consultants, must be shared face-to-face, within the context of shared values and experience. This construct is supported 
by Davenport and Prusak (1998)'s technical and organizational infrastructure for formal and cyber $\mathrm{Ba}$, and by knowledge transfer's multiple channel condition for informal Ba. For our questionnaire survey, we used three categories of Ba: formal, informal and cyber. Formal Ba refers to the opportunities formally provided by the organization such as scheduled meetings and institutionalized work forums. Informal $\mathrm{Ba}$ consists of the opportunities for communication that are casual and not defined by the organization or work processes. Cyber Ba involves IT systems such as groupware, e-mail, intranet and databases.

Leadership. The third enabling factor, leadership, is defined as "the process of influencing others to understand and agree about what needs to be done and how to do it, and the process of facilitating individual and collective efforts to accomplish shared objectives” (Yukl, 2005, p. 8). By this definition, we can see that leadership is an organizational driver, arguably the most important one, which defines first the vision and values that organizations seek, and second how organizational members go about realizing these. This construct is in agreement with Davenport and Prusak (1998)’s senior management support.

Previous research has shown that the degree to which individuals process information is a function of motivation, opportunity and ability (MacInnis and Jaworski, 1989). Again, looking at the aforementioned definition, leadership can greatly affect the first two variables of motivation, a force that directs individuals toward goals, and opportunity, the extent to which a situation is conducive to achieving a desired outcome (MacInnis and Jaworski, 1989).

As knowledge is created in the pursuit of organizational goals, leadership will determine what kind of knowledge is sought and created by members. Our research focuses on two wellstudied styles of leadership: achievement-oriented leadership and people-oriented leadership (Stogdill et al., 1962; Katz et al., 1951). Achievement-oriented leadership stresses results and therefore may be less supportive of long-term KM behaviors, while people-oriented leadership highlights processes brought about by team dynamics and subordinates' idiosyncrasies and may consequently encourage knowledge sharing among members.

Organizational control. The fourth enabling factor, organizational control, comprises the different organizational traits that constrain organizational behavior, and in particular knowledge sharing and creation. They consist of clearly defined objectives, empowerment, 
and creative chaos. These clearly-defined objectives are consistent with Davenport and Prusak (1998)'s clarity of vision and language. Having clearly established objectives, both at the individual and corporate level, guides what knowledge is shared and created toward achieving organizational goals. In a turbulent environment with frequent personnel turnover, such as in sales, clearly defined objectives and roles provide a sense of direction and can help recover knowledge and lost skills (Lemon and Sahota, 2004). These common objectives are the basis of the organization which embodies a system of cooperative behavior whereby individuals share common goals (Simon, 1997).

Empowerment and creative chaos have been shown to be necessary conditions for the creation of knowledge (Nonaka and Takeuchi, 1995). Empowerment allows employees to freely seek new methods and knowledge, whereas creative chaos is a prerequisite for the creation of knowledge. Without chaos, a state of fluctuation, status quo is maintained and new knowledge and innovation cannot be created.

Work style. Work style, the last factor studied, describes whether organizational members emphasize individual pre-set work goals or relationships with other members. This construct is related to Davenport and Prusak (1998)'s modicum of process orientation described as having a good sense of one's customers, both internal and external, so that one can remain flexible enough to adjust to changing needs.

Schein (2004), who examined the basic assumptions of human activity and human relationships in organizational settings, stresses the relevance of Kluckhohn and Strodtbeck's (1961) dichotomy of cultures between individualistic and communitarian societies, also supported by Hofstede's (1980) comparative research on core cultural dimensions. He notes that in the former situation the group is individualistic and competitive, and that in the latter, the group is communitarian and cooperative. These basic shared assumptions are used in solving problems related to identity and role, power and influence, needs and goals, and acceptance and intimacy.

We propose that the former type of work style, grounded in individuality, leads to individual knowledge acquisition rather than organizational knowledge creation, and that the opposite is true for the latter type of work style which promotes harmonious team work and puts the interest of the group ahead of one’s own. 
In summary, innovation begins with the sharing of knowledge among diverse organizational members and stakeholders. In today's knowledge society, knowledge creation and innovation cannot be achieved by one organization, let alone one person; it requires collaboration among individuals across divisions and organizations, which is significantly influenced by the organizational factors described above. Although previous research has addressed a single or a few of these factors, there has been a lack of systematic and global research covering all these factors. This paper hopes to fill in this research gap with a quantitative analysis of a Japanese pharmaceutical company and its international subsidiaries. Our research model is proposed in the next section.

\section{HYPOTHESES AND RESEARCH MODEL}

This research hypothesizes that the four modes of knowledge management are subject to several organizational forces beyond the explicit knowledge-related policies instigated by the firm and its management. Based on the previous literature review, we propose that organizational culture, Ba, leadership, organizational control, and work styles affect knowledge management, and we seek to assess their influence in four different countries. The following research model is derived from the previous discussion on the influence of organizational factors on knowledge management (Figure 1).

Insert Figure 1 here

We do not propose definite hypotheses so as to which constructs positively or negatively affect knowledge management, but we rather seek to compare the importance of these organizational forces for each local office.

\section{QUANTITATIVE ANALYSIS}

\section{Methodology}

Sample and data collection. The following quantitative analysis uses a questionnaire conducted with a Japanese pharmaceutical corporation, referred to as JPC, and its international 
subsidiaries. JPC, founded in 1941 in Japan, can be qualified as a medium-sized company with yearly sales of about USD 7 billion (FY2009) covering both prescription and over-the-counter drugs. Since 1989, the global corporate mission of JPC is to be a "human healthcare company," or "hhc," where employees' first consideration is the welfare of patients and their families. On its web site, JPC states that hhc "is shared by all employees and rises above nationalities, national borders, gender, and age”. JPC has also rolled out a global KM initiative to harness, focus and promote the knowledge creation power of its global group as a whole. It is a program designed to achieve a group-wide culture and identity of innovation. The global survey that is analyzed in this paper is part of the effort to measure the success of this initiative.

The quantitative analysis is drawn from a 78-item questionnaire, using a 5-point Likert scale, conducted in 2005. The questionnaire itself was developed over several years with the collaboration of professors of knowledge management from several Japanese National Universities. JPC recognized early the value of KM in creating innovation and conducts frequent surveys of its entire global workforce covering topics such as knowledge management and organizational control. Although the questionnaire was conducted with JPC's entire global workforce, we focus here on the four countries - Japan, the United States, France, and China - with the largest number of respondents. We also retain respondents only in the business functions common to these four locations - thus excluding manufacturing and research and development activities - in order to make cross-country comparisons valid and meaningful.

Indeed, JPC has been involved in knowledge management initiatives for more than 10 years and has a dedicated team that monitors and implements relevant projects aimed at boosting the yield of KM activities. Previous similar surveys conducted internally at JPC have demonstrated a steady improvement in knowledge management perceptions and behaviors among Japanese workers, as measured by the SECI survey instrument. The present performance of KM at the Japanese head office is proof that KM can be successfully improved through a corporate-wide policy of integrating KM into basic business processes.

The total number of respondents for the targeted business functions and countries was 2,666, with JPC's head office making up a large majority, 78.8\% (2,099 respondents), while 
the United States accounted for 13.3\% (355); China, 5.8\% (154); and France, 2.2\% (58) of respondents.

Selection and operationalization of constructs. In order to select relevant constructs, we adopted an exploratory approach in which several factor analyses were conducted with each subset of questions pertaining to knowledge management and organizational factors.

The knowledge management section uses tested questions from established research (Nonaka, 1994) and includes 6 questions for each of the four modes of the SECI process. These dependent constructs have already been subjected to factor analysis (Nonaka, et al., 1994), and are consistent with the theoretical basis of this work. Higher scores for socialization, externalization, combination, and internalization reflect higher levels for these knowledge management activities. Factor analyses with varimax rotation of independent constructs - organizational culture, Ba, leadership, organizational control, and work style were carried out (Table 1) to ensure that the questions displayed highest loadings on the intended constructs.

Insert Table 2 here

For organizational culture, two factors, which were consistent with our initial constructs, with eigenvalue above 1 were generated. The loadings show that there were eight questions in factor 1, and four in factor 2. Factor 1 corresponds to an open culture in which employees can openly raise questions and feel at ease, and explains about 31\% of the total variance. Factor 2 is consistent with a bureaucratic culture in which people are on their guard and decisions come slowly, and explains about $16 \%$ of the total variance. These two factors together explain roughly $47 \%$ of the total variance.

For $\mathrm{Ba}$, three factors with eigenvalue above 1 were generated. These revealed that the questions on Ba could be grouped into three factors consistent with our intended constructs. The loadings show that there were six questions for factor 1, three for factor 2 and three for factor 3. Factor 1 corresponds to formal $\mathrm{Ba}$, the organization-defined formal opportunities for interaction with others, and explains about $24 \%$ of the total variance. Factor 2 is consistent with cyber Ba, which is associated with opportunities for interaction through electronic media, 
and explains about $16 \%$ of the total variance. Factor 3 defines informal $\mathrm{Ba}$, which refers to the casual opportunities in organizations to interact with others, and explains about $15 \%$ of the total variance. These three factors alone explain about 56\% of the total variance.

For leadership, two components with eigenvalue above 1, which were consistent with our initial proposition, were generated. The loadings show that there were two questions for each factor. Factor 1 corresponds to people-oriented leadership, and explains about $43 \%$ of the total variance. Factor 2 is consistent with achievement-oriented leadership, which is related more to setting high goals and assessing results rather than on processes, and explains about $32 \%$ of the total variance. These two factors together explain about $76 \%$ of the total variance.

For organizational control, a confirmatory principal component analysis, with the number of factors set to four, revealed that the questions on organizational control were consistent with our intended constructs. The factor loadings show that there were seven questions for factor 1 , five for factor 2, three for factor 3, and four for factor 4 . Factor 1 corresponds to clear and widely recognized individual objectives, and explains roughly $24 \%$ of the total variance. Factor 2 is consistent with clear and widely recognized corporate objectives, and explains about 19\% of the total variance. Factor 3 addresses employee empowerment in terms of the extent to which they can set their own targets and pursue their own ideas, and explains about $11 \%$ of the total variance. Factor 4 reflects creative chaos in terms of frequent changes and overlap, and explains about $8 \%$ of the total variance. These four factors together explain about $62 \%$ of the total variance.

For work style, two factors, consistent with the intended constructs, with eigenvalue above 1 were generated. The loadings show that there were four questions in each factor. Factor 1 corresponds to self-directed work style, and explains about 31\% of the total variance. Factor 2 is consistent with a work-style that reflects consideration for others in accomplishing daily tasks, and explains about 32\% of the total variance. These two factors together explain about $64 \%$ of the total variance. However, in order to refine our analysis and based on the questions' content, work styles were further divided into self-directed vision, self-directed work method, others-oriented relations, and others-oriented emotional consideration. 


\section{Descriptive Statistics}

As shown in Figure 2, the knowledge conversion modes of JPC's head office in Japan are balanced across socialization, externalization, combination and internalization, while those of the United States, France, and China display a U-shaped pattern in which socialization and internalization score higher (standardized mean) than externalization and combination. This difference between the scores of Japan and the three other countries can be explained by the knowledge management initiatives that JPC has taken over the past 10 years to improve the balance of SECI. This will be examined further in the discussion.

\section{Insert Figure 2 here}

Cyber Ba in the United States and Japan is much higher than in France and China due the differential access to IT equipment and software. Informal Ba appears consistent across the four countries sampled. Also, the United States, France and China display higher achievement-oriented leadership relative to people-oriented leadership, while in Japan, both types of leadership are comparable. Japan and China show equal others-oriented and selfdirected vision work styles, while the United States and France display a sharp gap with significantly higher others-oriented work style relative to self-directed vision work style. The Japanese sample depicts the highest empowerment, while the French sample reveals the lowest.

\section{Regression Analysis}

Multiple regression analyses were performed for each country' sample with the five organizational factors - Ba, leadership, organizational culture, organizational control, and work styles - as independent variables, and the four knowledge conversion modes as the dependent variables (refer to Tables 2 to 5). The explanatory power of the research model (Figure 1) was evaluated based on the amount of variance in the dependent constructs for which the model could account $\left(\mathrm{R}^{2}\right)$. Each hypothesis corresponds to a path in the research model. Thus, support for each hypothesis could be determined by examining the sign (positive or negative) and statistical significance for its corresponding path. The absolute value of the 
beta coefficient indicates which of the independent variables have a greater impact on the dependent variable (knowledge conversion modes) in each multiple regression analysis.

In the Japanese sample (valid $\mathrm{N}=2,018$ ), the research model explains $48 \%$ of the variance for socialization, $42 \%$ for externalization, $32 \%$ for combination, and $42 \%$ for internalization $(\mathrm{p}<0.001)$. These exceeded 10\% that was proposed by Falk and Miller (1992) as indication of substantive explanatory power. Informal Ba displays the strongest effect on socialization, while work style with a self-directed vision strongly correlated with externalization, combination, and internalization $(\mathrm{p}<0.001)$ (Table 2).

\section{Insert Table 3 here}

In the U.S. sample (valid N=329), the research model explains 25\% of the variance for socialization, $23 \%$ for externalization, $16 \%$ for combination, and $34 \%$ for internalization $(\mathrm{p}<0.001)$. Formal Ba alone shows the strongest significant effect on socialization $(\mathrm{p}<0.001)$ and internalization $(\mathrm{p}<0.001)$, while both formal $\mathrm{Ba}$ and open culture equally affect externalization and combination $(\mathrm{p}<0.001$ or $\mathrm{p}<0.05)$ (Table 3$)$.

\section{Insert Table 4 here}

In the Chinese sample (valid $\mathrm{N}=126$ ), the research model explains $16 \%$ of the variance for socialization ( $\mathrm{p}<0.05), 22 \%$ for externalization $(\mathrm{p}<0.001), 16 \%$ for combination $(\mathrm{p}<0.05)$, and $13 \%$ for internalization $(\mathrm{p}<0.05)$. $\mathrm{Ba}$ in general explains the most variance in all four knowledge conversion modes. Formal Ba shows the strongest effect on socialization $(\mathrm{p}<0.05)$, externalization $(\mathrm{p}<0.05)$, and internalization $(\mathrm{p}<0.05)$, and cyber $\mathrm{Ba}$ on combination $(\mathrm{p}<0.05)$ (Table 4).

Insert Table 5 here

In the French sample (valid $\mathrm{N}=44$ ), the research model explains $38 \%$ of the variance for socialization ( $p<0.05)$, 29\% for externalization $(p<0.05)$, 39\% for combination $(p<0.05)$, and $43 \%$ for internalization $(\mathrm{p}<0.05)$. Clear individual objectives show the strongest effect on 
socialization and externalization, formal Ba on combination, and clear corporate objectives on internalization $(\mathrm{p}<0.05)$ (Table 5).

Insert Table 6 here

Table 6 summarizes the findings of the multiple regression analyses assessing the effects of organizational culture, $\mathrm{Ba}$, leadership, organizational control, and work styles on knowledge management for the Japanese, U.S., Chinese, and French samples.

Insert Table 7 here

\section{DISCUSSION}

\section{Japanese Headquarters Sample}

The KM initiative was started first at the Japanese corporate head quarters in 1998, and accordingly is vastly more sophisticated and deeply rooted in the Japan office. This is reflected in the results of the statistical analysis of the survey data, with the Japanese sample being much more active in the knowledge management processes as defined by Nonaka's SECI model.

The most striking characteristic of the Japanese sample in terms of the factors measured in the survey can be clearly seen in Figure 2. With regard to all factors, the Japanese sample showed the most balance for the factors related to SECI, organizational culture, Ba, leadership, organizational control, and work style. Japanese managers in charge of the survey stated that in the early years of KM training, the survey results for each of the modes of SECI at the Japan head office were not balanced, and that socialization and internalization, both individual-oriented modes of SECI, exhibited the largest scores, similar to those for the other surveyed subsidiaries. Over time, as training for KM became institutionalized at the head quarters, employees began exhibiting balanced SECI behaviors. This balance is essential for achieving significant creation of new organizational knowledge, as organizational knowledge must be shared and created through interaction with other organizational members. In other words, externalization and combination must accompany socialization in order to create new 
knowledge at the organizational level. JPC managers expressed that they are satisfied with the results of the current survey and hope to match this at other international subsidiaries with continued training. In addition to SECI factors, other factors also exhibited a balanced score for the Japanese sample.

The second remarkable result for the Japanese sample is the impact that a self-directed work style has on the KM modes of externalization, combination and internalization. This might be thought as counter-intuitive: it is easy to consider that an others-oriented work-style, rather than a self-directed work style, might be more conducive toward organizational KM. However, our interpretation is that due to the maturity of KM initiatives at the JPC head office and the fact that Japanese culture is group-oriented at its base, fruitful KM was realized to a greater extent when individual members were self-motivated toward a clear goal. Interviews with JPC persons have supported this interpretation.

As discussed above, JPC’s employees have fully adopted KM initiatives, contributing to the corporation's financial performance over the last nine years. We can also get a feel for value created by employees and their contribution to JPC's success by its industry-high pay scale. President, a leading Japanese business magazine for executives, reported that in its 2008 survey of industry pay scales, JPC had the highest in the pharmaceutical industry with an average annual pay of over 11 million yen (President, 2008).

\section{American Sample}

The US subsidiary of JPC was established in 1995 and marketed its first products in 1997. It achieved rapid growth to become an integrated pharmaceutical business with sales of approximately \$3 billion in fiscal year 2006. Starting in 2005, JPC made a concentrated and conscious effort to anchor its human health care mission and its knowledge management policies into its subsidiary.

As we can see in the descriptive statistics of Figure 2, the US subsidiary exhibited higher scores than any other country for all factors excluding, informal $\mathrm{Ba}$, empowerment and bureaucratic culture. We can interpret this as the subsidiary having strong culture, leadership, and operating styles. This is confirmed by managers at JPC. We can also see that the four modes of knowledge creation as defined by the SECI model are not balanced: there is a strong bias toward socialization and internalization, both of which are individual-oriented modes of 
knowledge creation. In contrast, externalization and combination, which involve sharing knowledge with other organizational members, have significantly lower scores. From the results of the early surveys at the Japanese head quarters, JPC managers state that this reflects the general ignorance of knowledge management initiatives at the US subsidiary, which only began SECI training in 2005, the year of the survey.

In terms of the regression analysis shown in Table 1, the four modes of SECI were most correlated with formal $\mathrm{Ba}$, which can be interpreted as the immaturity of KM in the subsidiary. Knowledge is shared in formal situations such as in meetings, which is only natural as the main aim of formal meetings at any firm is to share information and knowledge. In contrast, the US subsidiary doesn't share knowledge informally (informal Ba) or by using information and communication technologies (cyber $\mathrm{Ba}$ ). This result also is not surprising considering typical business practices and corporate culture in the United States. Compared to employees at Japanese firms, US employees may tend to have a more cut and dry approach to their job and employer, and may spend less time communicating informally with their co-workers. In Japanese firms, employees are routinely engaging in group activities: going out for dinner or drinks after work with co-workers is a normal occurrence at Japanese firms, and many employees feel that this is a vital practice for achieving a sense of group identity and for gaining important insights on both work issues and organizational politics (Hodgetts and Luthans, 2003).

However, looking at the strong scores for achievement-oriented leadership, othersoriented work style, clear individual objectives, clear corporate objectives for the US subsidiary, we feel that the company has a good starting foundation for knowledge sharing and creation. Leadership and objectives are necessary to guide the knowledge sharing and creation process, and consideration toward fellow workers is a necessary precondition for proactive knowledge sharing. The low score for empowerment, however, is one of the major weak points in terms of creating new knowledge. Practical organizational knowledge is created by individuals in the front lines of business, who must feel empowered to search for new answers and solutions. 


\section{Chinese Sample}

The Chinese office of JPC was opened in 1996 around the same time as the French office. Unlike the American and French samples, the Chinese sample displays the lowest externalization among the four SECI modes. It is important to note that the deficient cyber Ba can be explained in part by the low rate of PC and network equipment rate. A medium positive correlation between bureaucratic culture and creative chaos $(\mathrm{R}=0.63, \mathrm{p}<0.001)$ reveals positive organizational tension for knowledge creation (not shown here). Indeed, individuals in the Chinese subsidiary must balance the stability of a vertical organization and the uncertainty of change related to a fast-growing market.

The regression model, which although significant, provides the lowest explanatory power among the four countries, and reveals that Ba alone - either formal, informal, or cyber - is significantly responsible for most variance among the four knowledge conversion modes. This finding suggests that Chinese workers at JPC are most sensitive to the "shared context in motion" in the sharing and creation of knowledge. Ba is especially relevant for Confucian cultures where the family is the prototype of all social organizations (Hofstede and Hofstede, 2005). In such a culture, a person is not primarily an individual, but rather a member of a group or family.

\section{French Sample}

The French subsidiary of JPC was created in 1996 and has been run by the same doctor ever since. From its inception the French office adopted the hhc vision committed to highquality care respecting patients and their dignity. This JPC office is unique in the way that it is structured and managed by its autocratic CEO who is involved in every decision. Furthermore, the size of the French office (less than 60 people) makes this paternalistic style of management possible. The French sample displays the lowest SECI scores across all four countries and in particular very low externalization and combination, which suggest that JPC's French associates work in "silos", sharing very little knowledge. This finding is consistent with a strong autocratic leader from whom workers follow orders. It is further substantiated when taking into account the lowest mean scores for empowerment and creative chaos which inhibit knowledge workers from taking initiatives in knowledge sharing activities. In addition, the French subsidiary displays very low cyber Ba compared to formal and informal Ba, which can 
be explained by the absence of a sophisticated corporate intranet unlike its Japanese and American counterparts.

The regression analysis shows that clear individual objectives strongly affect both socialization and externalization, that formal $\mathrm{Ba}$ contributes to combination, and that clear corporate objectives influence internalization. These three organizational factors - clear individual and corporate objectives and formal $\mathrm{Ba}$ - are consistent with a top-down organization characterized by strong leadership. These findings suggest that, in highlystructured organizations in which the leader is involved at every level, knowledge management heavily relies on the opportunities created by the autocratic boss which substitute for the initiatives of its subordinates.

\section{CONCLUSION}

This analysis reveals that deliberate and continued training on knowledge management, as demonstrated in the Japanese head office, contributes to creating more balanced knowledge conversion modes (SECI). Also, little or no specific training on knowledge management results in a classic U-shaped pattern of knowledge conversion modes, with much lower levels of externalization and combination in comparison to socialization and internalization. It is important to note that these two deficient modes are central to knowledge sharing and creation on an organizational level, as these are the modes that involve other organizational members and the organization as a whole.

Each subsidiary, although part of the same corporate group and including the same functional teams, displayed very different patterns of knowledge management and organizational features. The regression model showed that different organizational factors especially $\mathrm{Ba}$, work styles, and organizational control - were responsible for the resulting knowledge management profiles of each local office: formal $\mathrm{Ba}$ in the U.S. office, clear objectives in the French subsidiary, formal Ba in the Chinese branch, and a self-directed vision in the Japanese head office.

Although these findings are specific to the company surveyed here, they justify the development of tailored strategies taking into account the organizational idiosyncrasies of each office in order to increase the efficiency of knowledge management efforts. This is 
especially relevant for multi-national companies which must adjust to local differences in their efforts to achieve consistent and global knowledge management effectiveness.

\section{REFERENCES}

Barney, J.B. (1996) 'The Resource-based Theory of the Firm', Organization Science 7(5): 469-476.

Baskerville, R., Dulipovici, A. (2006) 'The theoretical foundations of knowledge management’, Knowledge Management Research \& Practice, 4: 83-105.

Cartwright, D. (1951) Field Theory in Social Science: Selected Theoretical Papers by Kurt Lewin. New York, NY: Harper Torchbooks.

Chen, C. and Huang, J. (2007) 'How organizational climate and structure affect knowledge management - The social interaction perspective', International Journal of Information Management 27(2): 104-118.

Chuang, S. (2004) 'A Resource-Based Perspective on Knowledge Management Capability and Competitive Advantage: an Empirical Investigation', Expert Systems with Applications 27: 459-465.

Collis, D.J. and Montgomery, C.A. (1995) 'Competing on Resources: Strategy in the 1990s’, Harvard Business Review, July-August: 118-128.

Davenport, T. and Prusak, L. (1998) Working Knowledge: How Organizations Manage What They Know. Boston, MA: Harvard Business Press.

Davenport, T., De Long, D.W. and Beers, M.C. (1998) 'Successful Knowledge Management Projects', Sloan Management Review 39(2): 43-58.

Earl, M. (2001) ‘Knowledge Management Strategies: Toward a Taxonomy’, Journal of Management Information Systems 18(1): 215 - 242.

Eisenhardt, K.M. and Martin, J.A. (2000) 'Dynamic Capabilities: What Are They?' Strategic Management Journal 21(10/11): 1105-1121.

Falk, R.F. and Miller, N.B. (1992) A Primer for Soft Modeling. Akron, OH: University of Akron Press. 
Grant, R.M. (1991) 'The Resource-Based Theory of Competitive Advantage: Implications for Strategy Formulation’, California Management Review, Spring: 114-135.

Hodgetts, R. and Luthans, F. (2003) International Management: Culture, Strategy and Behavior $5^{\text {th }}$ ed. New York, NY: McGraw-Hill Higher Education.

Hofstede, G. (1980) Culture's Consequences. Beverly Hills, CA: Sage Publications.

Hofstede, G. and Hofstede, G.J. (2005) Cultures and Organizations: Software of the Mind. New York, NY: McGraw-Hill.

Jordan J. and Jones P. (1997) ‘Assessing your Company’s Knowledge Management Style’, Long Range Planning 3(3): 392-398.

Katz, D., Maccoby, N., Gurin, G. and Floor, L. (1951) Productivity, supervision, and morale among railroad workers. Ann Arbor, MI: University of Michigan.

Kluckhohn, F.R., Strodtbeck, F.L. (1961) Variations in Value Orientations. New York, NY: Harper Collins.

Kolb, A.Y., Kolb, D.A. (2005) 'Learning Styles and Learning Spaces: Enhancing Experiential Learning in Higher Education', Academy of Management Learning and Education 4(2): 193-212.

Kusunoki, K., Nonaka I. and Nagata A. (1998) 'Organizational Capabilities in Product Development of Japanese Firms: A Conceptual Framework and Empirical Findings', Organization Science 9(6): 699-718.

Lee, H. and Choi, B. (2003) 'Knowledge Management Enablers, Processes, an Integrative View and Empirical Examination', Journal of Management Information Systems 20(1): 179-228.

Leidner, D.E. (1998) 'Organization and Information Cultures in Knowledge Management Initiatives', 6th European Conference on Information Systems, panel presentation, Aix-en-Provence.

Lemon, M., Sahota, P.S. (2004) 'Organizational Culture as a Knowledge Repository for Increased Innovative Capacity’, Technovation, 24(6): 483-498. 
MacInnis, D.J., Jaworski, B.J. (1989). 'Information processing from advertisements: toward an integrative framework', Journal of Marketing, 53: 1-23.

Magnier-Watanabe, R., Senoo, D. (2008) 'Organizational Characteristics as Prescriptive Factors of Knowledge Management Initiatives', Journal of Knowledge Management 12(1): 21-36.

Malhotra, A., Majchrzak, A. (2004) 'Enabling Knowledge Creation in Far-Flung Teams: Best Practices for IT Support and Knowledge Sharing', Journal of Knowledge Management 8(4): 75-88.

Marrow, A.J. (1977) The Practical Theorist: The Life and Work of Kurt Lewin. New York, NY: Teachers College Press.

Nonaka, I. (1994) 'A Dynamic Theory of Organizational Knowledge Creation', Organization Science 5(1): 14-37.

Nonaka, I. and Konno, N. (1998) 'The Concept of Ba: Building Foundation for Knowledge Creation’, California Management Review 40(3): 40-54.

Nonaka, I. and Takeuchi, H. (1995) The Knowledge-Creating Company: How Japanese Companies Create the Dynamics of Innovation. New York, NY: Oxford University Press.

Nonaka, I., Byosiere, P., Borucki, C.C. and Konno, N. (1994) 'Organizational Knowledge Creation Theory: A First Comprehensive Test', International Business Review 3(4): 337-351.

Polanyi, M. (1966) Tacit Dimension. Gloucester, MA: Peter Smith.

Prahalad, C.K. and Hamel, G. (1990) 'The Core Competence of the Corporation', Harvard Business Review, May-June: 79-91.

President (2008) 'Nihon Jin No Kyuryo’ (Japanese Compensation), President Inc., December 3.

Riera, C.G., Senoo, D., Iijima, J. (2009) 'A Study of the Effect of Knowledge Creating Capabilities on Corporate Performance', International Journal of Knowledge Management Studies 3(1/2): $116-133$. 
Robbins, S. (2000) Organizational Behavior International Edition. Upper Saddle River, NJ: Prentice Hall.

Ruggles, R. (1998) 'The State of the Notion: Knowledge Management in Practice', California Management Review 40(3): 80-89.

Schein, E.H. (2004) Organizational Culture and Leadership. San Francisco, CA: JosseyBass.

Shimizu, H. (1995) 'Ba-Principle: New Logic for the Real-Time Emergence of Information', Holonics 5(1): 67-79.

Simon, H.A. (1997) Administrative behavior (4 ${ }^{\text {th }}$ Edition). New York, NY: The Free Press.

Stogdill, R.M., Goode, O.S. and Day, D.R. (1962) 'New leader behavior description subscales’, Journal of Psychology 54: 259-269.

Teece, D.J., Pisano, G. and Shuen, A. (1997) 'Dynamic Capabilities and Strategic Management', Strategic Management Journal 18(7): 509-533.

Turner, K.L. and Makhija, M.V. (2006) 'The role of organizational controls in managing knowledge’, Academy of Management Review 31(1): 197-217.

Von Krough, G., Ichijo, K. and Nonaka, I. (2000) Enabling Knowledge Creation: How to Unlock the Mystery of Tacit Knowledge and Release the Power of Innovation. New York, NY: Oxford University Press.

Yukl, G. (2005) Leadership in Organizations, 6th Edition. Upper Saddle River, NJ: Pearson Prentice Hall.

Zack, M. (1998) 'An Architecture for Managing Explicit Knowledge', Proceedings of the 6th European Conference on Information Systems, Aix-en-Provence: 86-99. 


\begin{tabular}{|c|c|}
\hline $\begin{array}{c}\text { Organizational } \\
\text { Factors }\end{array}$ \\
\begin{tabular}{|c|} 
Organizational \\
culture
\end{tabular} \\
\hline \hline $\mathrm{Ba}$ \\
\hline \hline Leadership \\
\hline \hline $\begin{array}{c}\text { Organizational } \\
\text { control }\end{array}$ \\
\hline \hline Work styles \\
\hline Combination \\
\hline Internalization \\
\hline
\end{tabular}

Figure 1: Research Model

Table 1: Results of factors analyses of independent constructs

\begin{tabular}{llccc}
\hline Constructs & Factors & Items & \% of variance & Cumulative \% \\
\hline Organizational & Open & 8 & 30.867 & \multirow{2}{*}{47.111} \\
culture & Bureaucratic & 4 & 16.244 & \\
\hline \multirow{3}{*}{ Ba } & Formal Ba & 6 & 24.273 & \multirow{2}{*}{55.304} \\
& Cyber Ba & 3 & 16.261 & \\
\multirow{2}{*}{ Leadership } & People-oriented & 3 & 15.304 & \multirow{2}{*}{75.683} \\
& Achievement-oriented & 2 & 43.266 & \\
\multirow{2}{*}{ Organizational } & Clear individual objectives & 7 & 32.417 & \multirow{2}{*}{62.897} \\
control & Clear corporate objectives & 5 & 24.114 & \\
& Empowerment & 3 & 19.394 & \multirow{2}{*}{63.515} \\
\multirow{2}{*}{ Work style } & Creative chaos & 3 & 8.372 & \\
& Self-directed vision & 4 & 31.377 & \\
& Others-oriented & 4 & 32.138 & \\
\hline
\end{tabular}




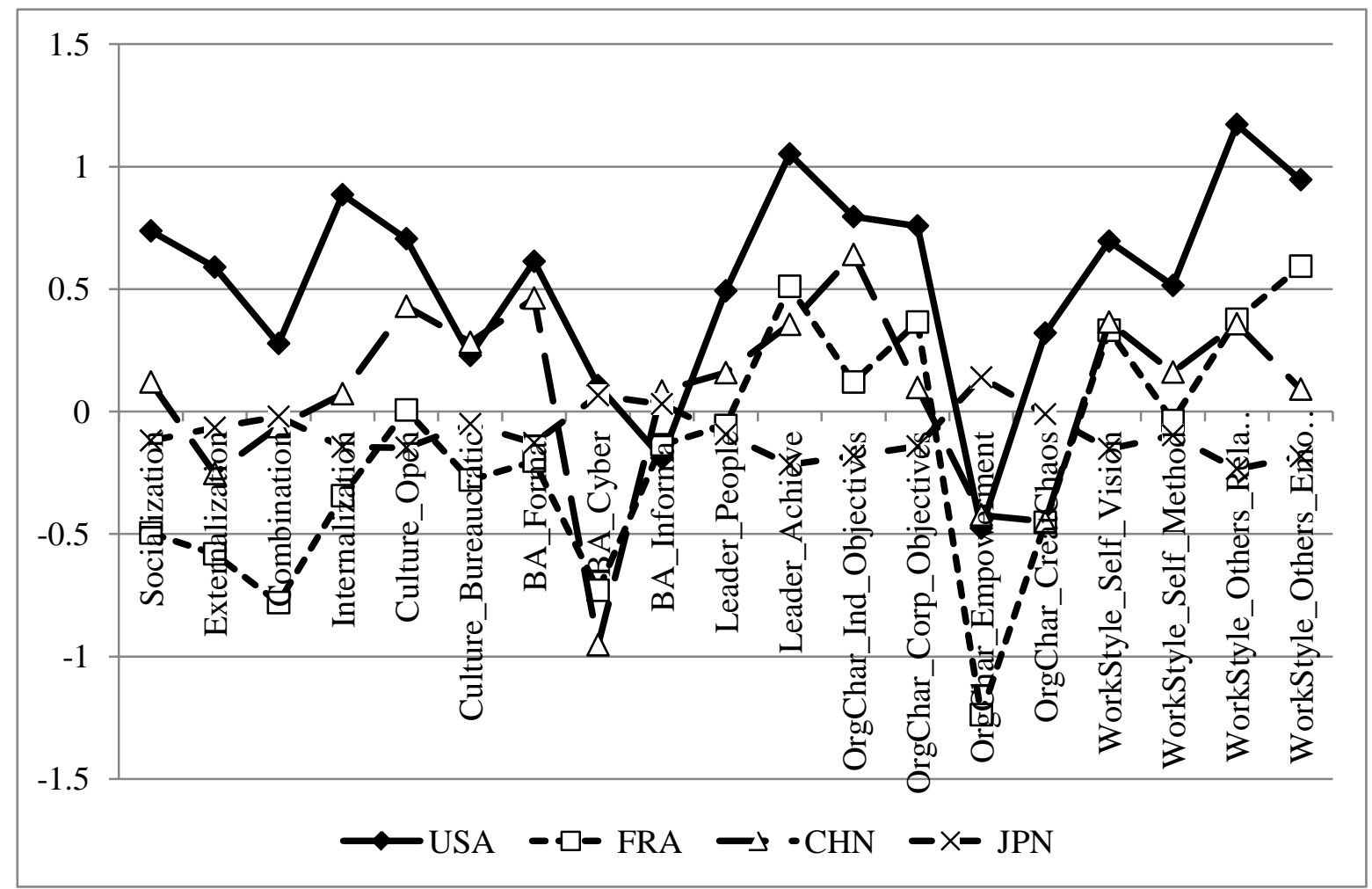

Figure 2: Standardized mean scores of SECI and organizational factor constructs

Table 2: Results of the multiple regression analysis for the Japanese sample

\begin{tabular}{lllll}
\hline & $\begin{array}{l}\text { Socialization } \\
\text { Jeta }\end{array}$ & $\begin{array}{l}\text { Externalization } \\
\text { Beta }\end{array}$ & $\begin{array}{l}\text { Combination } \\
\text { Beta }\end{array}$ & $\begin{array}{l}\text { Internalization } \\
\text { Beta }\end{array}$ \\
\hline Culture_Open & $.157^{* *}$ & $.181^{* *}$ & $.176^{* *}$ & $.151^{* *}$ \\
Culture_Bureaucratic & .033 & $.060^{*}$ & $.043^{*}$ & -.016 \\
Ba_Formal & $.206^{* *}$ & $.219^{* *}$ & $.130^{* *}$ & $.233^{* *}$ \\
Ba_Cyber & $.096^{* *}$ & $.092^{* *}$ & $.166^{* *}$ & $.074^{* *}$ \\
Ba_Informal & $.307^{* *}$ & $.219^{* *}$ & $.137^{* *}$ & $.130^{* *}$ \\
Leader_People & -.025 & -.036 & $-.053^{*}$ & $-.056^{*}$ \\
Leader_Achieve & $.052^{*}$ & .031 & $.053^{*}$ & $.060^{* *}$ \\
OrgCont_Clear_Indiv_Obj & -.037 & -.100 & -.045 & -.017 \\
OrgCont_Clear_Corp_Obj & -.020 & -.017 & -.009 & .014 \\
OrgCont_Empowerment & -.021 & -.006 & -.011 & -.021 \\
OrgCont_CreatChaos & $.051^{*}$ & .033 & $.049^{*}$ & $.055^{*}$ \\
WorkStyle_Self_Vision & $.246^{* *}$ & $.236^{* *}$ & $.211^{* *}$ & $.275^{* *}$ \\
WorkStyle_Self_Method & $.084^{* *}$ & $.093^{* *}$ & $.153^{* *}$ & $.087^{* *}$ \\
WorkStyle_Others_Relation & $.072^{* *}$ & $.082^{* *}$ & .020 & $.073^{* *}$ \\
WorkStyle_Others_Emotions & .011 & $.040^{*}$ & -.007 & $.042^{*}$ \\
\hline Adjusted R & $0.479^{* *}$ & $0.421^{* *}$ & $0.324^{* *}$ & $0423^{* *}$ \\
\hline
\end{tabular}

${ }^{*} \mathrm{p}<0.05 ;{ }^{* *} \mathrm{p}<0.001$ 
Table 3: Results of the multiple regression analysis for the American sample

\begin{tabular}{lllll}
\hline & Socialization & $\begin{array}{l}\text { Externalization } \\
\text { Beta }\end{array}$ & $\begin{array}{l}\text { Combination } \\
\text { Beta }\end{array}$ & $\begin{array}{l}\text { Internalization } \\
\text { Beta }\end{array}$ \\
\hline Culture_Open & .048 & $.195^{*}$ & $.150^{*}$ & .067 \\
Culture_Bureaucratic & $.115^{*}$ & .047 & $.122^{*}$ & $.132^{*}$ \\
Ba_Formal & $.222^{* *}$ & $.193^{* *}$ & $.148^{*}$ & $.238^{* *}$ \\
Ba_Cyber & $.113^{*}$ & .002 & .050 & $.108^{*}$ \\
Ba_Informal & $.167^{* *}$ & $.151^{*}$ & $.111^{*}$ & .020 \\
Leader_People & -.054 & -.104 & -.024 & -.004 \\
Leader_Achieve & .064 & .064 & .051 & .044 \\
OrgCont_Clear_Indiv_Obj & .011 & .029 & .026 & .108 \\
OrgCont_Clear_Corp_Obj & $.125^{*}$ & .119 & .093 & $.138^{*}$ \\
OrgCont_Empowerment & .044 & .085 & .002 & .000 \\
OrgCont_CreatChaos & .071 & .046 & .078 & -.024 \\
WorkStyle_Self_Vision & -.002 & .004 & .020 & .017 \\
WorkStyle_Self_Method & $.137^{*}$ & $.119 *$ & .088 & $.123^{*}$ \\
WorkStyle_Others_Relation & $.116^{*}$ & .095 & .007 & .104 \\
WorkStyle_Others_Emotions & .076 & .006 & .067 & $.166^{*}$ \\
\hline Adjusted R & $0.252^{* *}$ & $0.232^{* *}$ & $0.155^{* *}$ & $0.337^{* *}$ \\
\hline \multicolumn{1}{c}{${ }^{*}$ p $<0.05 ; * *$ p $<0.001$} & & & &
\end{tabular}

Table 4: Results of the multiple regression analysis for the Chinese sample

\begin{tabular}{lllll}
\hline Chinese Sample & Socialization & Externalization & $\begin{array}{l}\text { Combination } \\
\text { Beta }\end{array}$ & $\begin{array}{l}\text { Internalization } \\
\text { Beta }\end{array}$ \\
\hline Culture_Open & .107 & .171 & -.043 & .124 \\
Culture_Bureaucratic & .119 & .144 & .205 & .186 \\
Ba_Formal & $.272^{*}$ & $.247^{*}$ & .011 & $.240^{*}$ \\
Ba_Cyber & .073 & .109 & $.182^{*}$ & $.202^{*}$ \\
Ba_Informal & $.255^{*}$ & $.169^{*}$ & .141 & .148 \\
Leader_People & .134 & .049 & .061 & .020 \\
Leader_Achieve & -.064 & -.099 & -.089 & -.098 \\
OrgCont_Clear_Indiv_Obj & -.146 & -.098 & .137 & -.020 \\
OrgCont_Clear_Corp_Obj & .016 & .072 & .169 & .070 \\
OrgCont_Empowerment & .033 & -.017 & .095 & .006 \\
OrgCont_CreatChaos & -.021 & .138 & .182 & -.061 \\
WorkStyle_Self_Vision & .062 & .180 & .079 & .140 \\
WorkStyle_Self_Method & .085 & .051 & .231 & -.013 \\
WorkStyle_Others_Relation & -.089 & -.062 & -.194 & -.091 \\
WorkStyle_Others_Emotions & .158 & .095 & -.039 & .138 \\
\hline Adjusted R & $0.157^{*}$ & $0.219^{* *}$ & $0.162^{*}$ & $0.128^{*}$ \\
\hline
\end{tabular}

${ }^{*} \mathrm{p}<0.05 ;{ }^{* *} \mathrm{p}<0.001$ 
Table 5: Results of the multiple regression analysis for the French sample

\begin{tabular}{lllll}
\hline & Socialization & Externalization & Combination & Internalization \\
French Sample & Beta & Beta & Beta & Beta \\
\hline Culture_Open & .006 & .090 & -.167 & .020 \\
Culture_Bureaucratic & .061 & .125 & -.003 & .114 \\
Ba_Formal & .295 & .227 & $.442 *$ & .204 \\
Ba_Cyber & -.061 & -.114 & .164 & -.130 \\
Ba_Informal & .108 & -.057 & .125 & .033 \\
Leader_People & -.278 & -.084 & -.239 & -.212 \\
Leader_Achieve & $.407^{*}$ & .243 & .264 & .311 \\
OrgCont_Clear_Indiv_Obj &. $\mathbf{4 6 8 *}$ & $.366^{*}$ & $.419^{*}$ & .277 \\
OrgCont_Clear_Corp_Obj & .102 & .146 & $.372^{*}$ & $.395^{*}$ \\
OrgCont_Empowerment & .128 & .151 & .328 & .262 \\
OrgCont_CreatChaos & -.005 & -.019 & .039 & -.026 \\
WorkStyle_Self_Vision & .319 & .195 & .338 & .246 \\
WorkStyle_Self_Method & -.286 & -.170 & -.335 & -.115 \\
WorkStyle_Others_Relation & -.055 & .299 & .218 & .173 \\
WorkStyle_Others_Emotions & $.403^{*}$ & .046 & .060 & .035 \\
\hline Adjusted R & $0.384^{*}$ & $0.294^{*}$ & $0.393^{*}$ & $0.428^{*}$
\end{tabular}

Table 6: Summary of results

\begin{tabular}{lllll}
\hline & JPN & USA & CHN & FRA \\
\hline Socialization & Informal Ba & Formal Ba & Formal Ba & Clear ind. obj. \\
Externalization & $\begin{array}{l}\text { Self-directed } \\
\text { Vision }\end{array}$ & $\begin{array}{l}\text { Formal Ba } \\
\text { Open culture }\end{array}$ & Formal Ba & Clear ind. obj. \\
& Self-directed & Formal Ba & Cyber Ba & Formal Ba \\
& Vision & Open culture & & \\
Internalization & Self-directed & Formal Ba & Formal Ba & Clear corp. obj. \\
& Vision & & & \\
\hline
\end{tabular}

